\title{
Analisis dan Perancangan Aplikasi Kepuasan Klien Berdasarkan Model Servqual (Studi Kasus: PT. Longvin Indonesia)
}

\author{
${ }^{1}$ Cecep Kurnia Sastradipraja, ${ }^{2}$ Aris Subagja, ${ }^{3}$ Dea Kris Sintiana Putri \\ ${ }^{4}$ Haerul Ramadan, ${ }^{5}$ Raziya Mutasim \\ 1,2,3,4,5Sistem Informasi, Universitas Nusa Putra, indonesia \\ cecep.kurnia@nusaputra.ac.id, arissubagia@gmail.com, chrissputri@gmail.com, \\ haerul ramadansi17@nusaputra.ac.id, raziyamutasim2@gmail.com
}

\section{ARTICLE INFO \\ Article History: \\ Received : 05-09-2019 \\ Revised : 17-11-2019 \\ Accepted : 19-11-2019 \\ Online : 30-11-2019 \\ Keywords: \\ Service, Client Satisfaction, Servqual Method}

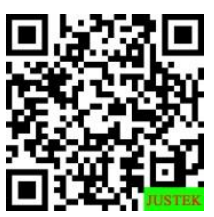

\begin{abstract}
Abstract: This research aims to analyze and develop service information systems on client satisfaction at PT. Longvin. This is because of PT. Longvin in-service evaluation, manual delivery, and distribution of questionnaires. The process of developing information systems using the waterfall model includes system requirements analysis, system modeling through defining context diagrams, data flow diagrams, and relational entity diagrams. Implementation of the system using the programming language PHP and MySQL as a management database. For the analysis of service quality measurement using the servqual model. System testing uses BlackBox testing and questionnaire-based system evaluation with data processing and measurement methods using a Likert scale. Based on the case study the system can display total tables, average tables, suggestions for improvements, and the results of calculating service quality quickly. User evaluation results show a percentage of $82 \%$ with the decision to agree with the application being built.
\end{abstract}

\begin{abstract}
Abstrak: Penelitian ini bertujuan untuk menganalisis dan mengembangkan sistem informasi kualitas layanan terhadap kepuasan klien pada PT. Longvin. Hal ini dikarenakan PT. Longvin dalam pengolahan evaluasi layanan, penilaian dan penyebaran kuesioner yang masih dilakukan secara manual. Adapun proses dalam pengembangan sistem informasi menggunakan waterfall model meliputi analisis kebutuhan sistem, pemodelan sistem melalui pendefinisan diagram konteks, diagram alir data, dan diagram entitas relasional. Implementasi sistem menggunakan bahasa pemrograman PHP dan MySQL sebagai manajemen basis data. Untuk analisis pengukuran kualitas layanan menggunakan model servqual. Pengujian sistem menggunakan blackbox testing, sedangkan evaluasi sistem berbasis kuesioner dengan pengolahan dan pengukuran data menggunakan skala likert. Berdasarkan studi kasus sistem mampu menampilkan tabel total, tabel rata-rata, saran perbaikan dan hasil perhitungan service quality dengan cepat. Hasil evaluasi pengguna menunjukkan prosentase $82 \%$ dengan penilaian setuju terhadap aplikasi yang dibangun.
\end{abstract}

\section{A. LATAR BELAKANG}

Setiap perusahaan pada hakikatnya memiliki motif untuk mendapatkan keuntungan yang besar (Tsamara et al., 2019), tetapi kecenderungan umum adalah perusahaan sering mengabaikan nilai asset dari pelanggan atau klien (Pujihastuti, 2007) yang 
memiliki peranan penting yaitu membantu usaha dan keberlangsungan perusahaan untuk mencapai tujuan tersebut, sehingga perhatian dan layanan terhadap klien menjadi berkurang. Namun seiring waktu kualitas layanan telah menjadi topik dan pembahasan penting mengingat korelasinya yang signifikan dengan keuntungan, penghematan biaya dan pangsa pasar (Merkert \& Assaf, 2015; Talluri et al., 2013).

Tidak terkecuali pada sektor layanan industri manufaktur dimana terdapat konsensus yang berkembang bahwa kepuasan klien menjadi indikator yang penting atas kualitas layanan dan banyak perusahaan mencari berbagai cara untuk mengubah layanan dan pemeliharaan klien melalui inisiatif peningkatan kualitasnya (Al-Damen, 2017), akan tetapi tentu saja untuk dapat menyajikan kualitas unggul dari layanan merupakan proses yang tidak mudah untuk diwujudkan, proses penting yang harus dibangun oleh organisasi adalah proses bagi klien (Emerson et al., 2013). Setiap tingkat manajerial di perusahaan harus memperhatikan dalam memahami perilaku konsumen yang menggunakan layanan mereka. Bagaimana persepsinya konsumen dan bagaimana konsumen mengevaluasi pelayanan menjadi masukan penting dalam proses untuk membangun kualitas layanan yang unggul (Emerson et al., 2013).

Hal tersebut bisa saja terjadi pada PT. Longvin sebagai industri manufaktur yang memproduksi alat-alat elektronik di kawasan Sukabumi, dimana jika perusahaan hanya berfokus terhadap produksi masal dan pedistribusian tanpa disertai adanya penanganan untuk media penilaian layanan dan pemeliharaan atas kliennya maka yang terjadi adalah tidak adanya peningkatan jumlah produksi diakibatkan permintaan produk yang menurun dari pemegang merk atas kurangnya minat dari pengguna akhir. Berdasarkan studi obeservasi dan wawancara yang dilakukan penulis, PT. Longvin dalam menganalisis kualias layanan terhadap kepuasan klien masih dilakukan secara manual dengan menggunakan alat bantu Ms. Excel. Dengan mengacu pada permasalahan tersebut penulis menemukan peluang yang bisa ditawarkan untuk penanganan kepuasan klien dan pengaruh kualitas layanannya secara terkomputerisasi yang dapat diaplikasikan pada PT. Longvin Indonesia.

Berdasarkan uraian di atas, penelitian ini bertujuan untuk menganalisis dan merancang sistem informasi kepuasan klien berbasis servqual dengan studi kasus pada PT. Longvin sehingga menghasilkan sebuah prototipe sistem informasi analisis untuk mengetahui faktor atau dimensi kualitas layanan yang memiliki pengaruh pada tingkat ekspetasi klien dengan merujuk pada dimensi kualitas layanan servqual.

\section{B. METODE PENELITIAN}

Metode yang digunakan dalam penelitian ini adalah pendekatan kualitatif, yaitu penelitian yang dimaksudkan untuk memahami kejadian mengenai yang apa dialami subyek secara deskripsi melalui bentuk kata dan bahasa, pada suatu konteks yang alamiah disertai penggunaan berbagai metode ilmiah (Moleong, 2017). Teknik analisis data melalui pendekatan kualitatif dilaksanakan melalui wawancara (Rachmawati, 2017) yang bertujuan untuk menerangkan sifat variable yang sedang diteliti. Adapun variabel pada penelitian ini adalah variabel independen (kualitas layanan PT. Longvin Indonesia) dan dependen (kepuasan klien PT. Longvin Indonesia). Dalam mengevaluasi prototype sistem yang dibangun dilakukan pengujian usability dengan metode regresi sederhana yaitu pendekatan kualitatif yang dikuantitatifkan (Sugiyono, 2012) melalui penyebaran kuesioner dengan teknik pengolahan data pengukuran variable menggunakan skala likert.

Tahapan penelitian merupakan serangkaian proses atau tahapan yang dikerjakan dalam pelaksanaan riset (Gelling, 2015). Adapun tahapan pada penelitian ini dapat 
dilihat pada gambar 1. Dalam menentukan faktor (dimensi) kualitas pelayanan dalam bentuk kuesioner kepuasan klien menggunakan model Service Quality (Servqual) (Bakhtiar et al., 2012) dimana model service quality (Servqual) memiliki lima dimensi kualitas pelayanan yang mempengaruhi kepuasan klien, diantaranya (Utama, 2003) yaitu: Dimensi Tangibles, Dimensi Responsiveness, Dimensi Assurance, Dimensi Emphaty, dan Dimensi Realibility. Sedangkan untuk variabel terikat yaitu dimensi kepuasan klien. Perancangan pernyataan kuesioner ini mengacu pada metode Parasuraman Zeithaml Berry (Aliyadi, 2015). Perancangan pernyataan pada kuesioner kepuasan klien dapat dilihat Tabel 1 di bawah ini.

Tabel 1. Perancangan Pernyataan Kuesioner

\begin{tabular}{|c|c|c|}
\hline $\begin{array}{l}\text { Determinan } \\
\text { Tanaibles }\end{array}$ & \multicolumn{2}{|r|}{ Pernyataan } \\
\hline Tangibles & 1 & $\begin{array}{l}\text { PT.longvin memiliki armada yang baik dan cukup untuk } \\
\text { mendistribusikan produk }\end{array}$ \\
\hline & 2 & $\begin{array}{l}\text { PT. Longvin memiliki fasilitas penunjang yang baik, semisal Hotline } \\
\text { untuk pesanan dan keluhan. }\end{array}$ \\
\hline & 3 & $\begin{array}{l}\text { PT. Longvin selalu dilengkapi materi-materi menarik secara visual } \\
\text { yang berkaitan dengan layanannya, semisal brosur atau katalog. }\end{array}$ \\
\hline \multirow[t]{5}{*}{ Realibility } & 4 & $\begin{array}{l}\text { Apabila perusahaan berjanji untuk melakukan sesuatu pada waktu } \\
\text { yang ditentukan mereka akan menepati janjinya, semisal waktu } \\
\text { pengiriman barang. }\end{array}$ \\
\hline & 5 & $\begin{array}{l}\text { Apabila klien memiki masalah, perusahaan akan bersungguh-sungguh } \\
\text { membantu memecahkannya, semisal barang retur dan pembayaran } \\
\text { piutang. }\end{array}$ \\
\hline & 6 & Perusahaan memberikan pelayanannya secara tepat sejak awal \\
\hline & 7 & $\begin{array}{l}\text { Perusahaan menyediakan layanannya sesuai dengan waktu yang } \\
\text { dijanjikan. }\end{array}$ \\
\hline & 8 & Perusahaan selalu mengupayakan solusi bagi kliennya. \\
\hline \multirow[t]{4}{*}{ Responsiveness } & 9 & $\begin{array}{l}\text { Perusahaan memberitahu kliennya kapan barang pesanan akan } \\
\text { dikirim. }\end{array}$ \\
\hline & 10 & Perusahaan memberikan pelayanan yang cepat kepada para kliennya. \\
\hline & 11 & $\begin{array}{l}\text { Perusahaan selalu berusaha membantu para kliennya, semisal dalam } \\
\text { hal pemesanan dan pengiriman. }\end{array}$ \\
\hline & 12 & $\begin{array}{l}\text { Perusahaan tidak akan pernah mengabaikan respon dari kliennya, } \\
\text { semisal keluhan pengiriman, keluhan retur, pesanan, dan bonus. }\end{array}$ \\
\hline \multirow[t]{4}{*}{ Assurance } & 13 & $\begin{array}{l}\text { Perilaku pegawai dan manajemen perusahaan mampu membuat para } \\
\text { kliennya mempercayai mereka. }\end{array}$ \\
\hline & 14 & Klien perusahaan merasa aman dalam bertransaksi \\
\hline & 15 & $\begin{array}{l}\text { Pegawai perusahaan dan manajemen secara konsisten bersikap sopan } \\
\text { terhadap para klien. }\end{array}$ \\
\hline & 16 & $\begin{array}{l}\text { Pegawai dan manajemen perusahaan memiliki pengetahuan yang } \\
\text { memadai untuk menjawab pertanyaan-pertanyaan. }\end{array}$ \\
\hline \multirow[t]{3}{*}{ Emphaty } & 17 & Perusahaan selalu memberikan perhatian yang baik kepada kliennya \\
\hline & 18 & Perusahaan selalu mengutamakan kepentingan para kliennya. \\
\hline & 19 & Perusahaan selalu memahami kebutuhan para kliennya. \\
\hline
\end{tabular}

\section{HASIL DAN PEMBAHASAN}

a. Gambaran Desain Sistem

Gambaran Analisis konseptual desain sistem pada sistem informasi analisis layanan dan kepuasan klien PT. Longvin dapat dilihat pada Gambar 1 di bawah ini. 
b. Diagram Konteks

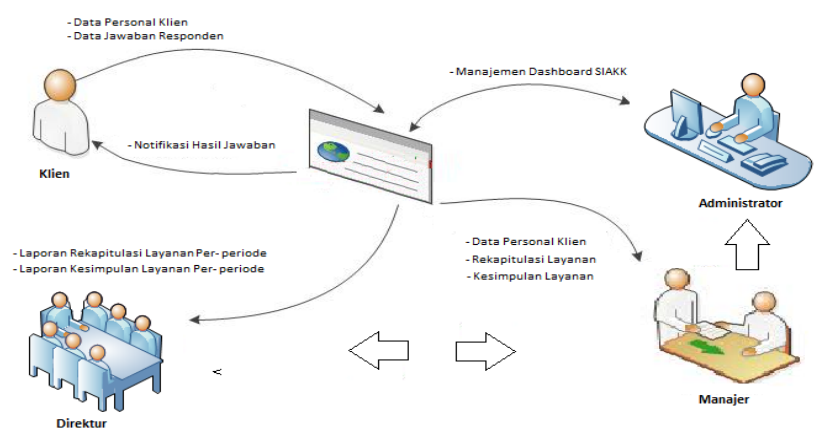

Gambar 1. Model Analisis Konseptual

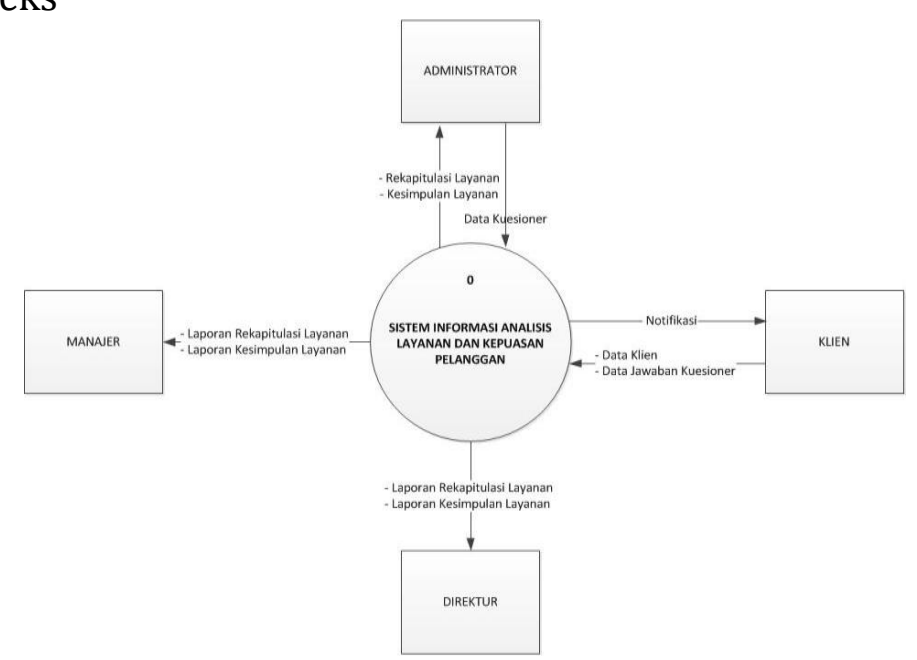

Gambar 2. Diagram konteks sistem analisis Layanan dan kepuasan klien c. DFD Level 0

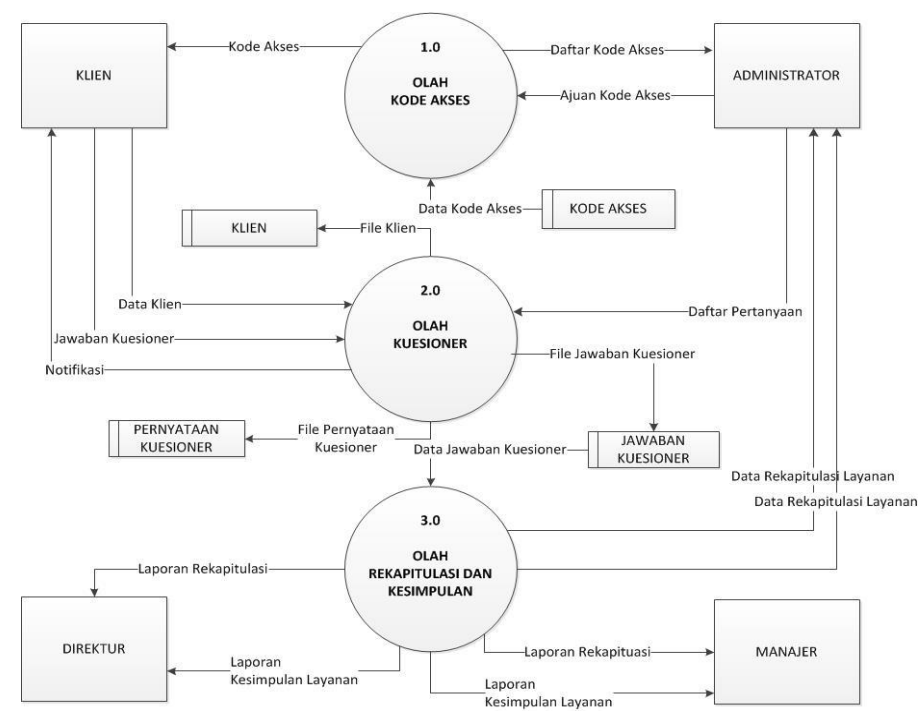

Gambar 3. DFD Level 0 Sistem Analisis Layanan dan Kepuasan Klien

d. Entitiy Relationship Diagram (ERD)

Menurut Kusumawati di dalam (Suhendro, 2017) menyatakan bahwa Entity Relationship Diagram adalah simbol grafis dalam pemodelan data konseptual yang menggambarkan hubungan antara penyimpanan. Berikut merupakan ERD yang dibangun yang ditunjukan pada gambar 4 di bawah ini. 
18 | Justek : JuRnal Sains Dan Teknologi | 2, No. 2, November 2019, Hal. 14-20

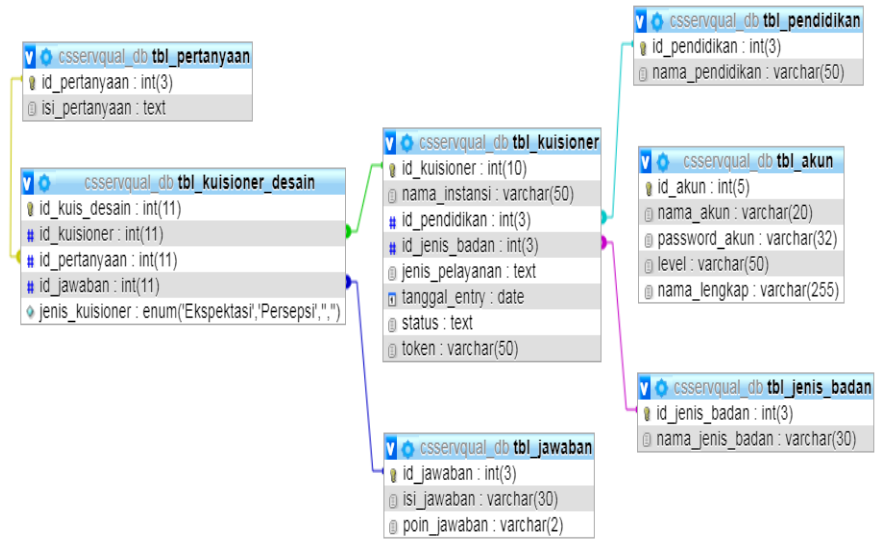

Gambar 4. ERD Sistem Analisis Layanan dan Kepuasan Klien

e. Desain Antarmuka Sistem

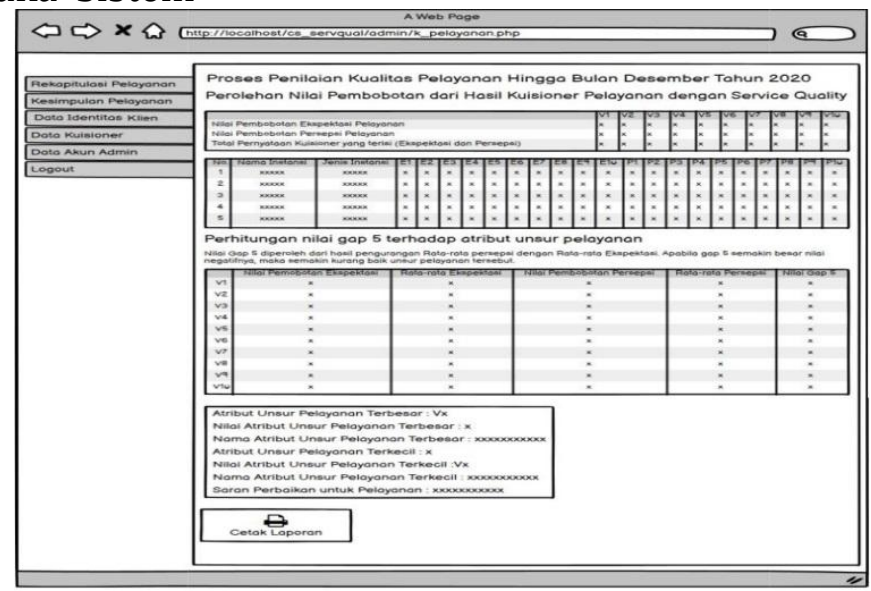

Gambar 5. Kesimpulan Pelayanan

f. Implementasi Sistem

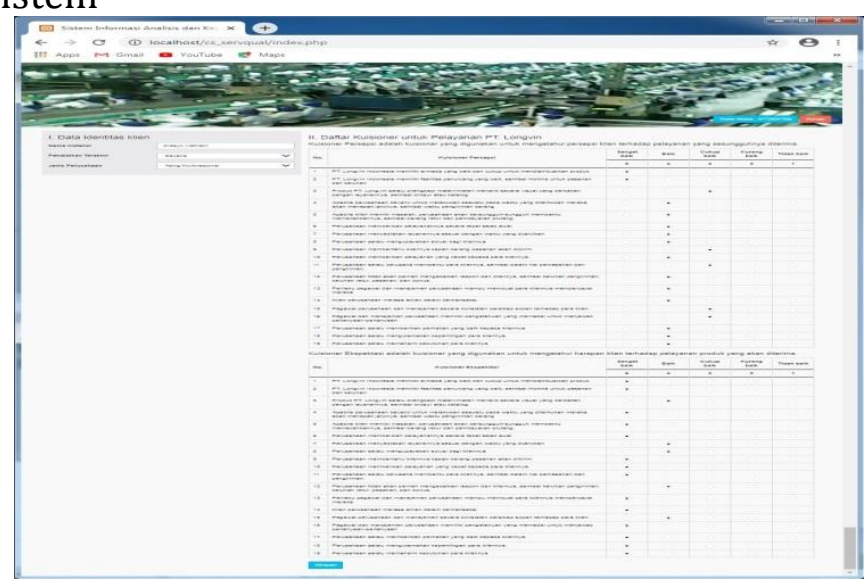

Gambar 6. Kuisioner Klien 


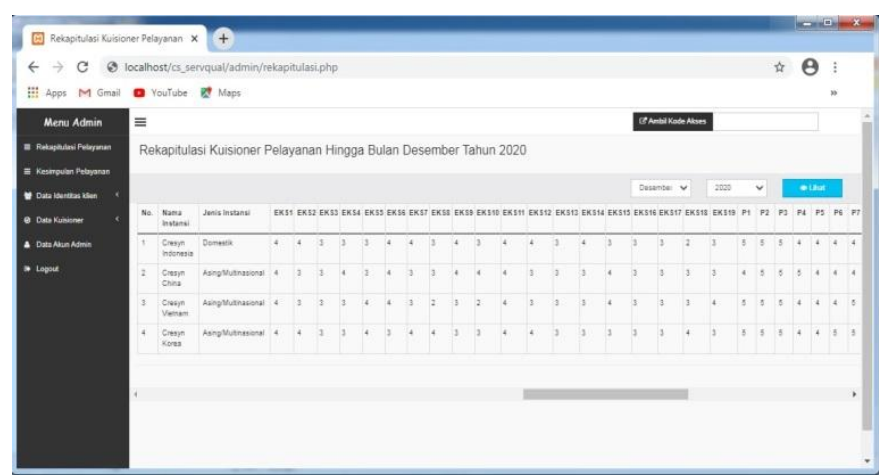

Gambar 7. Rekapitulasi Kuisioner Pelayanan

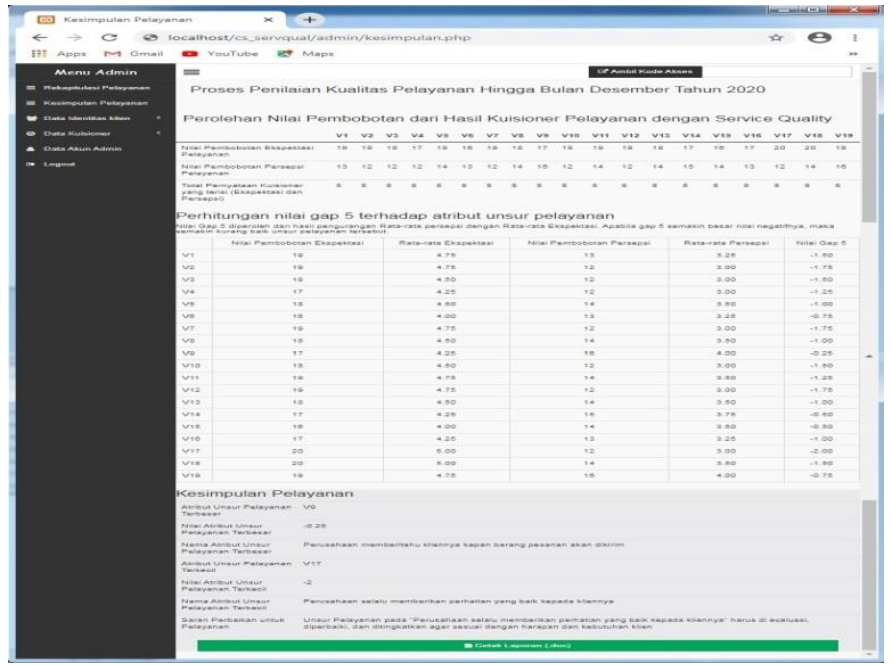

Gambar 8. Kesimpulan Pelayanan

g. Pengujian Blacbox

Berdasarkan uji fungsionalitas system yang dilakukan bahwa fungsi aplikasi berjalan baik melaui tahapan scenario pengujian dan telah sesuai dengan kebutuhan pengguna.

h. Pengujian Usability

Pengujian kegunaan merupakan teknik yang digunakan dalam mengevaluasi produk dengan mengujikannya kepada pengguna (Hertzum, 2016). Pengujian dilakukan dengan mengajukan kuisioner kepada 30 (tiga puluh) responden yang terdiri dari 5 (lima) pertanyaan. Berdasarkan pengolahan dan pegukuran data menghasilkan prosentase $82 \%$ yang menyatakan "setuju " atas aplikasi yang dibangun.

\section{SIMPULAN DAN SARAN}

Berdasarkan penelitian yang telah dilakukan menghasilkan sebuah prototipe sistem informasi yang mampu menampilkan hasil rekapitulasi dan kesimpulan atas layanan yang berpengaruh pada kepuasan klien yang dapat diimplementasikan pada PT. Longvin, Hasil evaluasi pengguna menunjukan prosesntase $82 \%$ menyatakan "setuju" terhadap aplikasi yang dibangun. Adapun saran penulis yaitu diharapkan adanya pengembangan perumusan atribut pernyataan dengan memperhatikan setiap perubahan proses bisnis yang ada dan kedepannya diharapkan adanya perbaikan atau pengembangan sistem informasi yang telah dihasilkan baik dengan menggunakan metode servqual atau metode lainnya seperti Quality Function Deployment (QFD). 


\section{REFERENSI}

Al-Damen, R. (2017). Health Care Service Quality and Its Impact on Patient Satisfaction "Case of Al-Bashir Hospital." International Journal of Business and Management. https://doi.org/10.5539/ijbm.v12n9p136

Aliyadi, A. (2015). Evaluasi Kualitas Layanan Sistem Informasi Akademik Dengan Metode Servqual (Studi Kasus Di Universitas Muhammadiyah Ponorogo). Jurnal Teknik, 4(1).

Bakhtiar, A., Susanty, A., \& Massay, F. (2012). Analisis Kualitas Pelayanan Yang Berpengaruh Terhadap Kepuasan Pelanggan Menggunakan Metode Servqual Dan Model Kano (Studi Kasus: PT. PLN UPJ Semarang Selatan). Analisis Kualitas Pelayanan Yang Berpengaruh Terhadap Kepuasan Pelanggan Menggunakan Metode Servqual Dan Model Kano (Studi Kasus: PT. PLN UPJ Semarang Selatan), 5(2), 77-84. https://doi.org/10.12777/jati.5.2.77-84

Emerson, E., McGill, P., \& Mansell, J. (2013). Severe learning disabilities and challenging behaviours: Designing high quality services. Springer.

Gelling, L. (2015). Stages in the research process. Nursing Standard (Royal College of Nursing (Great Britain): 1987), 29(27), 44-49. https://doi.org/10.7748/ns.29.27.44.e8745

Hertzum, M. (2016). Usability testing: too early? too much talking? too many problems? Journal of Usability Studies Archive, 11, 83-88.

Merkert, R., \& Assaf, A. G. (2015). Using DEA models to jointly estimate service quality perception and profitability - Evidence from international airports. Transportation Research Part A: Policy and Practice, 75, 42-50. https://doi.org/https://doi.org/10.1016/j.tra.2015.03.008

Moleong, L. J. (2017). Metodologi Penelitian Kualitatif (Edisi Revisi). In PT. Remaja Rosda Karya.

Pujihastuti, I. (2007). Customer Value Sebagai Sumberdaya Informasi Bagi Perusahaan. Optimal: Jurnal Fakultas Ekonomi Universitas Islam “45” Bekasi, 1(2).

Rachmawati, I. N. (2017). Pengumpulan Data Dalam Penelitian Kualitatif: Imami Nur Rachmawati.

Sugiyono. (2012). Metode Penelitian Kuantitatif, Kualitatif dan R \& D.Bandung:Alfabeta. Metode Penelitian Kuantitatif, Kualitatif Dan $R \quad \& \quad$ D.Bandung:Alfabeta. https://doi.org/10.1017/CB09781107415324.004

Suhendro, D. (2017). Perancangan dan Implementasi Realisasi Anggaran Pendapatan ( Studi Kasus: Pengadilan Negeri Klas IB Pematangsiantar ). Seminar Nasional Teknologi Informatika.

Talluri, S., Kim, M. K., \& Schoenherr, T. (2013). The relationship between operating efficiency and service quality: are they compatible? International Journal of Production Research, 51(8), 2548-2567. https://doi.org/10.1080/00207543.2012.737946

Tsamara, Y. N., Raharjo, S. T., \& Resnawaty, R. (2019). Strategi Tanggung Jawab Sosial Perusahaan (Csr) Pt Pertamina Melalui Program Kemitraan Dan Bina Lingkungan Dalam Pertamina Sehati. Share: Social Work Journal. https://doi.org/10.24198/share.v8i2.20083

Utama, A. (2003). Analisis Pengaruh Persepsi Kualitas Pelayanan Terhadap Kepuasan Pelanggan Rumah Sakit Umum Cakra Husada Klaten. Opsi, 1(2), 1-15. 